\title{
Moving Africa away from the global knowledge periphery: a case study of AJOL
}

\author{
Susan Murray*
}

\section{Introduction}

Bibliographies played a crucial role in education and research during the 'papyrocentric' era (when publishing and written communication were solely paper-based) as tools that allowed people to maintain systematic awareness of published formal research outputs of interest, and of how to locate these. Actually accessing the content summarized in bibliographies was often, if not usually, a challenge for African academics, however, due to African institutions being generally beset by substantial resource scarcity (with the exception of the larger universities in South Africa, and a handful in other African countries). This resulted in the bibliography, even a national one, being something of an unfulfilled wish list for Africans rather than a guide to assist access to readily available content. Decades of underinvestment in higher education on the African continent, and less developed countries in general, partly due to a 55-year World Bank policy determining that higher education was unimportant for economic growth in developing countries, ${ }^{1}$ resulted in a global scholarly information divide already entrenched before the advent of the internet.

Modern journal publishing is young within Africa, and essentially postcolonial. It suffered disproportionately from the crises in higher education in the late 1970 s and early 1980 s. The 1980 s were also an economically difficult time for many developing countries, so recovery in African scholarly research and communication was stifled. Until at least 2000, 'the international development community encouraged African governments' relative neglect of higher education. The World Bank, which exercises significant influence over developing country governments, has long believed that primary and secondary schooling are more important than tertiary education for economic development'. The World Bank's global education-sector spending was 17 per cent on higher education from 1985 to 1989, but this figure dropped to just 7 per cent from 1995 to $1999 .^{2}$

\footnotetext{
* Susan Murray is the Managing Director of African Journals OnLine (AJOL). Her academic qualifications are in development economics and her professional background has been in the non-profit sector in various African countries. Susan Murray's interests are in the role that access to scholarly information can play in development and poverty alleviation in low income and emerging economies.

${ }^{1}$ Bloom, D., D. Canning, and K. Chan (2005) Higher Education and Economic Development in Africa. Washington DC: World Bank, Harvard University.

${ }^{2}$ Bloom, D., D. Canning and K. Chan (2006) 'Higher Education and Economic Development in Africa', Harvard, <http://www.arp.harvard.edu/AfricaHigherEducation/Reports/BloomAndCanning. pdf>
} 
On the back of these lingering problems, the current information era, or computer age, has exacerbated the gap between developed and developing countries' access to information for research and education, in the form of the digital divide, despite the information age being characterized by an unprecedented, exponentially increasing proliferation of knowledge materials, both in the traditional formally published sense, and in new types of scholarly communication like wikis, blogs and video-recorded conference presentations. What of bibliographies in this current era and their role in increasing structured access to the plethora of scholarly information to, within and from Africa?

In attempting to provide at least a partial answer to this question, this essay uses the case study of African Journals OnLine (AJOL). Until 1 May 2009, AJOL was essentially a limited meta-data bibliography of peer-reviewed, African-published scholarly journals. But due to stakeholder requests, it has since expanded to include full text online and become a digital library. With over 350 partner titles, AJOL is the world's largest online collection of African journals. AJOL is increasingly focused on providing support to make Open Access publishing a viable model for its journal partners, along with trying to forge stronger partnerships and linkages with relevant initiatives on the African continent.

The essay will argue that increasing accessibility of African research outputs through Open Access, and sustained commitment to building partnerships, collaborations and networks amongst African stakeholders with linkages between these and their overseas counterparts are two pivotal and necessary conditions to move Africa away from the global knowledge periphery.

\section{Africa's multiple peripherality to the global knowledge system}

The world's second largest continent contains 54 countries and is enormously diverse, but despite the wide range of capacity and resources within and between these countries, an important and legitimate generalization can be made that strengthening research and research-publishing are crucial priorities for improving higher education in Africa. ${ }^{3}$ Since knowledge, access to information and higher education have been shown conclusively to be critical to economic development and long-term poverty alleviation, ${ }^{4}$ it is imperative for the continent that contains two-thirds of the 50 Least Developed Countries in the world to collectively overcome Africa's 'multiple peripherality' to the international knowledge system. ${ }^{5}$

Paul Otlet, one of the fathers of bibliography and information science, envisaged in 1934 that

Everything in the universe, and everything of man (sic), will be registered at a distance as it was produced. In this way a moving image of the world will be established, a true mirror of his (sic) memory. From a distance, everyone will be

\footnotetext{
${ }^{3}$ Teferra, D. and P.G. Altbach (2004) 'African higher education: Challenges for the $21^{\text {st }}$ century', Higher Education 47: 21-50.

${ }^{4}$ Bloom, D. et al., (2005).

${ }^{5}$ Altbach, P.G. (2003) 'African Higher Education and the World', in D. Teferra and P.G. Altbach (eds), African Higher Education: an international reference handbook. Bloomington: Indiana University Press.
} 
able to read text, enlarged and limited to the desired subject, projected on an individual screen. In this way, everyone from his (sic) armchair will be able to contemplate creation, as a whole or in certain of its parts. ${ }^{6}$

This was a remarkably prescient prediction of the internet as a knowledge collection for humanity. Although, as Guédon emphasized in 1994, it must be recognized that 'the visibility of electronic publications from the perspective of those who are not yet members of the electronic network is a key matter, and in this regard, indexing in the traditional bibliographic tools is crucial', 7 it is also important to acknowledge that the digital divide is lessening. It will not always be as big an obstacle as it is today. In the current information age, stakeholders working to shift Africa from the knowledge periphery need to include internet resources as an intrinsic tool, and furthermore to pay cognizance to new forms of scholarly communication, and, potentially, to African-defined measures of scholarly quality, rather than continuing to rely on those defined by the previous papyrocentric and Northern hegemonies.

Several online initiatives do exist to improve affordable access to scholarly information from the developed global North to Africa, such as INASP's PERii Programme, ${ }^{8}$ JSTOR's African Access Initiative, ${ }^{9}$ HINARI, ${ }^{10}$ AGORA $^{11}$ and OARE. ${ }^{12}$ However, while immensely valuable, this content does not necessarily provide relevant knowledge pertaining to context-specific issues in Africa. Since most publications included in these initiatives are published outside the continent; they are not directly or specifically Africarelevant. For the most part, except for publications from within their own country, it has always been easier for Africans to obtain publications from overseas than from the rest of Africa. An important longitudinal study conducted between 1996 and 1998 at the University of Ghana, Legon and the University of Zambia, found that although 'the majority of staff (just under 70 per cent) at both universities considered African-published journals equally or more important than those published elsewhere, with most (49 per cent) rating them equally important', most staff also 'felt their access to African-published journals was very limited'. ${ }^{13}$ The same study found that apart from journals locally published in their own countries, researchers did not know what other titles were available from the rest of Africa. One researcher's quote (from Alemna et al. in 1999) was particularly telling: 'My research is focused on Africa and I need more information. But African

\footnotetext{
${ }^{6}$ Otlet, P. (1934) Traité de documentation. Le livre sur le livre: théorie et pratique (1989, preprint). Liège: Centre de Lecture publique de la Communauté française.

${ }^{7}$ Guédon, J-C. (1994) 'Why are Electronic Publications Difficult to Classify?', Directory of Electronic Fournals, Newsletters and Academic Discussion Lists, Association of Research Libraries, <http:dlist.sire.arizona.edu/335/01/guedon.html>, accessed 5 August 2009.

${ }^{8}<$ http://www.inasp.info/file/5f65fc9017860338882881402dc594e4/perii.html>

${ }^{9}<$ http://www.jstor.org/page/info/participate/new/fees/africanAccess.jsp?cookieSet=1>

$10<$ http://www.who.int/hinari/en/>

$11<$ http://www.aginternetwork.org/en/>

$12<$ http://www.oaresciences.org/en/>

13 Alemna, A.A., V. Chifwepa and D. Rosenberg (1999) 'African Journals: an evaluation of the use made of African-published journals in African universities', Education Research 36, London:

Department for International Development.
} 
journals are harder to identify and obtain [than journals from developed countries].'

Along with resource scarcity, probably the most significant problem for authors and researchers in Africa has been the means to disseminate Africanpublished research widely. This has an obvious corollary of making it difficult for African and international researchers to access African-published works. There has been a paucity of indexing systems of African publications, ${ }^{14}$ leading to minimal African-published journal discovery.

Africa (and the rest of the world) needs access to African-published research, most particularly that done on locally relevant issues. The representation of African research within indexed Western publications is extremely low, at approximately 0.7 per cent of the total publications. ${ }^{15}$ This is not to say that research is not being conducted and published in Africa; it is highly likely that the volume of papers published in Africa is underestimated due to the content not being included in international indexes. Along with bibliometric analysis, numerous studies conducted during the last 10 to 15 years have also shown other areas of relative decline in research and scholarship at many African universities, such as the deterioration of research infrastructure, and a generally poor quality of library resources, with many universities not using automated management systems. ${ }^{16}$ Regarding bibliographies of African-published works, 'since bibliographic control at the national or regional (African) level leaves much to be desired, the contributions of African scholars may fail to reach readers in their own countries or elsewhere in Africa'. ${ }^{17}$

Notwithstanding the difficult consequences of over five decades of underinvestment in higher education in Africa, there are positive indications that the tide may finally be turning, through the onset of systemic efforts in public policy and spending shifts to support knowledge economies and higher education in African countries, and increased international support structures and efforts to assist this. Unfortunately, the World Bank's African Publishing Initiative (API) launched in 1997, which could have been one of these supports, has been stopped, with the reason given to AJOL as being lack of funding. However, the African Regional Action Plan on the Knowledge Economy (ARAPKE) by the African Union (AU) is 'a coordinated and multi-pronged strategy at both the national and sub-regional levels to roll out the knowledge economy in the continent ... and aims at

\footnotetext{
${ }^{14}$ Nwagwu W. (2005), 'Deficits in the Visibility of African Scientists: implications for developing information and communication technology (ICT) capacity', World Review of Science, Technology and Sustainable Development 2 (3 \& 4): 244-60.

${ }^{15}$ Cetto, A. M. (2001) 'The Contribution of Electronic Communication to Science - has it lived up to its promise?', Proceedings of the 'Second ICSU-UNESCO International Conference on Electronic Publishing in Science held in association with CODATA, IFLA, and ICSTI and UNESCO House', Paris, 20-23 February.

${ }^{16}$ Kotecha P. (ed.) (2008) Towards a Common Future: higher education in the SADC region. Research findings from four SARUA studies. Southern African Regional Universities (SARUA) Studies Series, <www.sarua.org>

${ }^{17}$ Lor, P.J. and J.J. Britz (2005) 'Knowledge Production from an African Perspective: international information flows and intellectual property', International Information and Library Review 37 (2): 61-76.
} 
building a region fully benefiting from ICT services by the year $2015{ }^{\prime}{ }^{18}$ ARAPKE has been developed on the basis of the vision defined by the New Partnership for Africa's Development (NEPAD) and the African Information Society Initiative (AISI), which is part of the United Nation's Economic Commission for Africa (ECA). The Association of African Universities (AAU) Regional Capacity Mobilisation Initiatives are another example of these encouraging developments. ${ }^{19}$ What matters is how these various initiatives will be translated into practice and the provision of tangible support for information and knowledge development programmes. The recent British Academy report on higher education collaborations with African institution ${ }^{20}$ was disappointing for its lack of attention to support for existing programmes. Despite AJOL's efforts thus far to get involved with the African Information Society Initiative, no progress has been made yet. So there is clear room for improvement in both developed and developing countries.

The limitations of internet connectivity to Africa are a major challenge, but are being eroded. From 2000 to 2008, the number of internet users in Africa grew by 1,100 per cent. ${ }^{21}$ It is only a matter of time before the low-earth orbit satellite efforts of Google, ${ }^{22}$ and new under-sea cables (SEACOM which landed in 2009 and the EASSY cable due in 2010) currently being laid along the east coast of Africa, amongst other initiatives, improve the speed and lower the cost of African internet connectivity. De-regulation to allow for competition between service providers to further lower costs, and a focus on in-country backbone infrastructure development to solve the 'last mile' connectivity challenge might take a little longer, but will come in time. In the short term, the development and rigorous application of institutional bandwidth usage monitoring and management policies could limit frivolous use of current connections, and dramatically improve the speed for university staff and legitimate use by students.

It is important that both African universities and governments address the shortage of skills to support scholarly communication in Africa, particularly promotion of ICT and computer programming qualifications. That said, AJOL believes that users of the software in Africa themselves should be more pro-active in teaching themselves how to use these tools through 'learning-bydoing', rather than passively awaiting training from 'some expert', which is often currently the case. As access to hardware and the internet increases, it is to be hoped that Africans increasingly take more responsibility for their own self-taught application expertise.

Even once the infrastructural, financial, institutional and skills related obstacles have been addressed in African countries, there still remains the challenge of actually doing the work of making information flow between African countries and from South to North, and assisting users in accessing

\footnotetext{
18 African Union Commission (2008) The African Regional Action Plan on the Knowledge Economy (ARAPKE) Flagship Projects (Phase One) p. 5.

${ }^{19}$ Kotecha, P. (ed.) (2008).

${ }^{20}$ The British Academy and the Association of Commonwealth Universities (2009) 'The Nairobi Report: frameworks for Africa-UK research collaboration in the social sciences and humanities', March.

$21<$ http://www.internetworldstats.com/stats1.htm\#africa>, accessed 1 August 2008.

22 Appfrica.net Webpage (2008) 'Google Backs Launch of 16 Satellites to bring 3bn Online', $<$ http://appfrica.net/blog/archives/434>
} 
the African-published works they find in bibliographies, and establishing systems and channels of communication. 'The question is: when we have bridged the digital divide, in which way will the traffic flow? ... Because the bibliographical control systems are mainly based in the North, scholarly communication from South to North is also essential to facilitate SouthSouth information flow. ${ }^{, 23}$ In addition, 'the African research community is also not as tightly knit as that in other regions. Problems of communication and networking prevent easy flow and exchange of ideas and information'. ${ }^{24}$ A shift in the way researchers work in Africa needs to take place as the information and communication technology infrastructure improves, in order to increase collaboration and strengthen research networks. There are many initiatives to make scholarly works from the developed global North available to the developing global South, but very few working to make content from the South available. AJOL is one of these few.

\section{Background to African fournals OnLine (AfOL)}

African Journals OnLine (AJOL) was initiated in May 1998 as a pilot project managed by the International Network for the Availability of Scientific Publications (INASP) ${ }^{25}$ At that time, the aim was to promote the awareness and use of African published journals in the sciences by providing access to tables of contents (TOCs) on the internet. The project was evaluated at the end of 1999. It was recommended that AJOL be continued and expanded to include more journals in more subject areas, as well as abstracts of articles.

At its re-launch as an ongoing INASP programme in August 2000, AJOL featured 50 English-language African-published journals in agricultural sciences, science and technology, health and social sciences. It also provided abstracts where available, and introduced a key word search service and a document delivery service for all titles. In March 2004, AJOL adopted a more sophisticated database system to increase the functionality of the site, and to ensure that AJOL is compatible with other research services offered on the web. AJOL uses amended open source software called Open Journal Systems (OJS), ${ }^{26}$ compiled by the Public Knowledge Project (PKP). ${ }^{27}$

In 2005, AJOL moved to African management and is now a not-for-profit company in its own right, based in South Africa. Three years later, in 2008, AJOL had grown to host over 350 African-published, peer-reviewed journals from 26 countries. The AJOL website is visited each month by over 80,000 researchers from all over the world. In its founding document as a South African Section 21 Not for Profit Company, AJOL exists in order to

promote, establish, protect, preserve and maintain an online library and archive of academic journals published throughout the continent of Africa, to provide online access to the journals for educational, research and cultural purposes and to provide a publishing service for African journals.

${ }^{23}$ Lor P.J. and J.J. Britz (2005) 'Knowledge Production from an African Perspective: international information flows and intellectual property', International Information and Library Review 37 (2): 61-76.

${ }^{24}$ Smart, P. (2005) 'African Journals Online (AJOL)', Serials Review 31 (4).

$25<$ http://www.inasp.info/>

$26<$ http://pkp.sfu.ca/?q=ojs $>$

$27<$ http://pkp.sfu.ca/> 
Journals are selected for inclusion on AJOL using the following criteria:

- they are scholarly in content, and contain original research (in addition to other content)

- their content is peer-reviewed and quality controlled

- they are able to provide all content for inclusion on AJOL in electronic format

- they guarantee permission from the authors to allow AJOL to operate a document delivery or download service

- they are published within the African continent. Management of publishing strategy, business development and production operation are all run from an African country.

AJOL provides a free service to the journals by hosting their content online, and actively promoting the website to encourage discovery of these titles and their articles. AJOL is a non-profit organisation whose mandate is to promote and increase online access to African research output and to support African scholarly publishing. This is done primarily via the provision of a central and globally available online platform, using open-source software, through which African journals and full-text articles can be accessed.

Until fairly recently, the ability to find and access scholarly, peer-reviewed African research was extremely difficult, if not impossible. ${ }^{28}$ The fact is that this is quickly changing as more and more African journals index their materials online, notably through AJOL. In a paper published by Jaygbay in 1998 Africa was estimated to have a total of 400 African scholarly journals from 48 of the African continent's countries. ${ }^{29}$ However, in the previous year, 1997, the African Periodicals Exhibit listed only 135 active and regularly published titles from 22 African countries. ${ }^{30} 3132$ In 2001 it was posited that the numbers of actively publishing African journals had declined even further. ${ }^{33}$ In 2009, these numbers cannot be accurate - while South Africa is by no means representative of the rest of the continent (quite the opposite, in fact), the South African Department of Education has accredited 243 scholarly journals in that country alone. ${ }^{34}$ Nigeria is another giant in journal

\footnotetext{
${ }^{28}$ Lagoze, C. (2004) 'Bridging the Past and Future: scholarly communication in the $21^{\text {st }}$ century', Russian Digital Libraries fournal 7 (3): 88-96, <http://www.cs.cornell.edu/lagoze/papers/Tsukuba\% 202004.pdf>

${ }^{29}$ Jaygbay, J. (1998) 'The Politics of and Prospects for African scholarly Journals in the Information Age', in Knowledge Dissemination in Africa: the role of scholarly journals. Chestnut Hill, MA: Bellagio, p 63-74.

${ }^{30}$ Zeleza, P.T. (1997) Manufacturing African Studies and Crisis. Dakar: CODESRIA.

${ }^{31}$ Zell, H.M. (1999) A Handbook of Good Practice in Fournal Publishing, $2^{\text {nd }}$ Edition. London and Oxford: International African Institute and African Books Collective.

32 Jaygbay, J. (1997) ‘African Scholarly Journals, Slow Decline or Quantum Jump?', LOGOS 8 (2): $85-9$.

33 Adbowale, S. A. (2001) 'The Scholarly Journal in the Production and Dissemination of Knowledge on Africa: exploring some issues for the future', African Sociological Review 5 (1): 1-16, <http://www.codesria.org/Links/Publications/contents_asr/asr_5_1.htm>

${ }^{34}$ Stellenbosch University Website (2007) 'Research pages - South African accredited journals', $<$ http://sun025.sun.ac.za/portal/page/portal/Administrative_Divisions/Navorsing/Research\% 20Home/Accredited\%20Journals/SAJournals2007.pdf>
} 
publishing on the continent. African Journals OnLine (AJOL), the world's largest web-based African scholarly journal aggregator, currently has 350 titles representing over 40,000 articles from 26 African countries, and AJOL is growing the number of partner titles on a monthly basis.

It should be noted that in spite of this, AJOL itself has yet to determine a satisfactory figure with regards to the number of scholarly journals currently in active publication within the African continent. The number of journals published in Africa is very low compared to other continents, which is a symptom of Africa's 'peripherality' from the global knowledge system. However, AJOL has found that almost 70 per cent of the journals it hosts online publish on a regular basis, remaining close to their intended publication frequencies. Those which do not are generally facing a wide range of problems halting the publication of future issues. These range from financial shortfalls to journal mismanagement to a lack of submissions of journal articles of adequate quality, and difficulties disseminating the journals at all, at least in hard copy.

'Digital libraries are a critical part of Africa's development, not a luxury.'35 Digital libraries will also play an important role in distance education using the internet; distance education being Africa's great chance to meet the demand for quality tertiary education. ${ }^{36}$ Scholarly journals remain a vital and entrenched means of academic communication. In the information age, providing electronic access to journals has become the norm if that research is to reach the international audience who need to be aware of it. In the information age, making African scholarly meta-data and full text comprehensively digitally accessible requires:

1) visibility (through aggregation, bibliographies, search-engine-optimized and high profile websites and marketing, promotion and awarenessraising)

AND

2) availability on the internet - preferably in full text (through online hosting and active journal commitment)

\section{AND}

3) usability (through sensible and pragmatic software design, logically organized information, hosting that allows fast download for those with good connectivity, and small file sizes that allow download for those with poor connectivity)

AND

4) affordability (through increasing the degree of openness of Africanpublished research output via Open Access and improved widespread understanding of new copyright and licensing options).

\footnotetext{
${ }^{35}$ Mambo, B. (2003) 'Digital Libraries in Africa: a review of developments since 1996', in M. Beebe, K.M. Kouakou, B. Oyelaran-Oyeyinka, M. Rao. (eds), Africa-dot-Edu: ITopportunities and higher education in Africa. New Delhi: Tata McGraw-Hill Publishing Company Limited.

${ }^{36}$ Saint, W. (2003) 'Tertiary Distance Education and Technology in Sub-Saharan Africa', in D. Teferra and P.G. Altbach (eds), African Higher Education: an international reference handbook. Bloomington: Indiana University Press.
} 


\section{Visibility on the internet}

While it is possible to use the free OJS software to host a journal online in isolation with relatively basic computer and internet skills, it is not possible for individual journal websites to attain the same high degree of visibility on the internet as with aggregation through a search-engine optimized service like AJOL. Aggregation is the key to greater visibility of African-published journals on the internet. The more journals that participate in the AJOL service, the higher the visibility of each of them.

Skilled and knowledgeable website designers are an important component of another essential element to increasing visibility online, namely ensuring that the site is search engine optimized. If the major search engines cannot locate a website easily, it will not be visited very often. The success of the internet in making African research more visible is illustrated not only in the increased use of AJOL, but also by the fact that the majority of the users found the website by using an internet search engine. The expectation that research information will be available on the internet has spread to researchers and students in less developed countries, and AJOL has become a recognized source of African research. For most of the journals on the service it comes at the top of any search results.

The AJOL service has very successfully managed to raise the visibility of all its participating journals. AJOL is usually in the top ten results of search strings relevant to the participating journals. As a result of AJOL's compliance with the Open Archives Initiative Protocol for Meta-data Harvesting, journal content listed with AJOL is now being indexed through Open Archives Initiative search engines dedicated to research, which collect the metadata for each journal article, making this readily available to a global audience, and giving the journals much greater visibility among the worldwide research community, even beyond AJOL itself. For example, AJOL is indexed by Google Scholar and many other databases. The AJOL website address is also included in the resource section of many hundreds of reputable university libraries and that of research organisations worldwide. AJOL is also a founding member of the WorldWideScience Alliance (www.worldwidescience.org), which provides a federated deep-web search tool to access research data, meta-data, and full text resources from all over the world. The increased visibility of the research on AJOL translates into increased potential for citation.

The majority of journals joining the service approach AJOL directly because they want to be included. The advantages of being showcased with other African journals are appreciated and information about the benefits of the service seems to be spreading by word of mouth among journal publishers. Many journals have informally reported that the number of submissions to their journals has increased, thus raising the standard of the content.

Now that it is possible to identify the number of visits to individual journals, it can be demonstrated that all the journals are being visited on the website and it is not just the more well known journals that receive visits. The rise of academic interest in health, agricultural and environmental issues is clearly demonstrated by the large number of users visiting these journals on AJOL, as well as by the preponderance of journals dealing with these disciplines. 
Articles supplied by the document delivery (now article download) service have increased dramatically over time. While most of the articles were supplied to African researchers initially, there has been a significant increase in the number being delivered to Asian countries which is very encouraging because it indicates the development of a South-South exchange of research information. This might also be due to the increased economic associations between Africa and the East, notably China and India. Researchers from the United States and the United Kingdom are, predictably, the largest customers from the High Income Countries.

A systemic benefit of increased online visibility of journals and bibliographies - although individual journals affected may not agree - is that duplication of journals might be reduced in the long term, since previously, similar journals were started with virtually the same focus and scope, simply because there was no awareness that another journal (sometimes with the same title) already existed, covering that specific topic. ${ }^{37}$ This duplication 'contributes to a problem of sustainability in an environment where the financial insecurity of maintaining publications is already a cancer'. 38

\section{Availability on the internet}

AJOL attempts to bridge the gap between the enormous higher education (and development) potential inherent in digital online technology, and the economic and other resource limitations that constrain African journals from using it to disseminate their content widely. AJOL's various free services to journal publishers and researchers help to decrease their costs in a way that brings a net reduction in the cost of online journal hosting and access. The sum of the costs of each African journal outsourcing the online hosting of their content in isolation would far outweigh the cost of AJOL doing so for multiple journals. In many cases, it would not be possible for journals to be available online without AJOL's assistance. And of course this is true of journals publishing generally; aggregation has become a key driving force in the electronic era.

One of the recommendations of evaluations of the AJOL initiative was that the availability of full text online, and not just access to bibliographic information, was important. As a result, AJOL's entire hard copy collection was digitized during late 2007 and 2008, and additional functionality added to the site to include full text. Once AJOL extended its functionality from an online bibliography of journals to a full-text library from May 2009, visits to the site increased by over 30 per cent. This is a clear indication of users' need for access to the full text, and not just to the bibliographic information of African-published research.

AJOL has recently signed an agreement with CrossRef $^{39}$ to add Digital Object Identifiers (DOIs) to full text articles of all participating journals. DOIs are increasingly used in references and bibliographies, as they are permanent links to items on the internet, even when the journal is moved to

\footnotetext{
37 Proud, L. and S. Murray (2009) 'African-published Scholarly Journals: open journal systems and alternative publishing models as used by African Journals OnLine', in S. Ngobeni (ed.) Scholarly

Publishing in Africa: opportunities and impediments. Pretoria: Africa Institute of South Africa.

${ }^{38}$ Smart, P. (2005).

$39<$ http://www.crossref.org/>
} 
be hosted elsewhere, for example. This will add to the permanence of availability, and there will be increased visibility through inclusion of DOIs of African-published research in electronic bibliographies, as DOIs provide for direct linking out to original articles, thus hopefully resulting in higher citation rates of African-published journals.

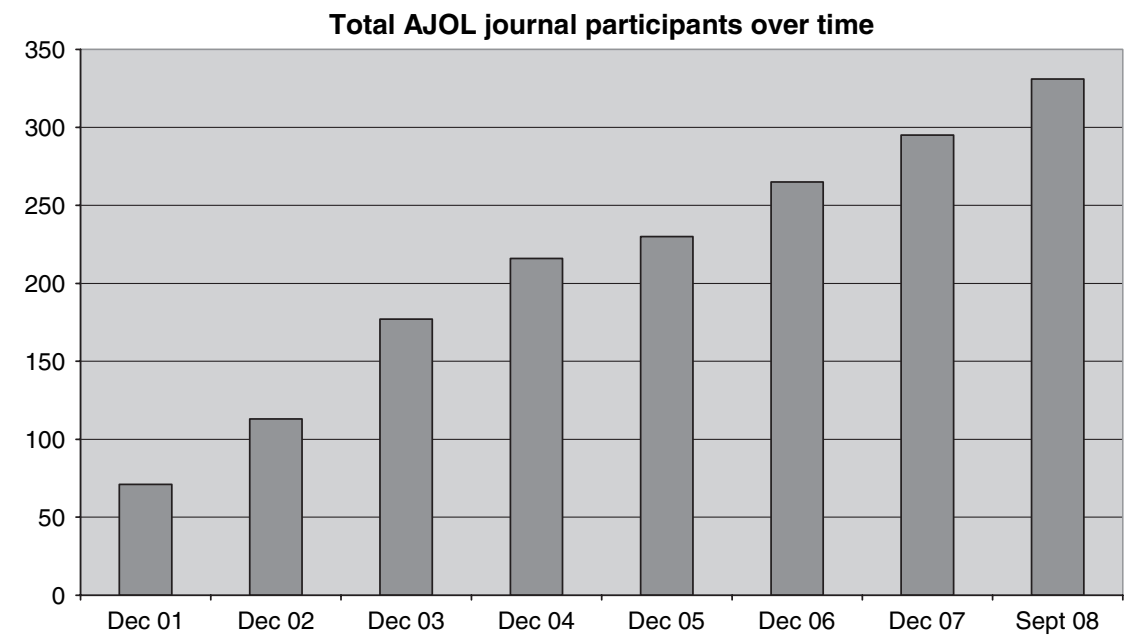

AJOL has achieved a growth of around 35 additional journals available per annum. This is steady growth, which AJOL intends to continue or improve on each year going forward. For the past few years, most journals joining AJOL have initiated contact, rather than the other way around. AJOL considers this a great achievement, as word of mouth about the service indicates value for the beneficiaries, and the fact that the service has gained critical mass.

AJOL is actively in communication with 241 of the 350 participants (69 per cent). There are 31 active journals that have not contributed content to AJOL since the beginning of 2007, although we know they remain extant. These journals have either not yet provided AJOL with their recently published issues, or have temporarily ceased publishing, but are expected to resume. The fact that one third of the journals that have joined AJOL since its inception in 1998 have not actively participated in AJOL since the beginning of 2007 or earlier, for whatever reason, is a disappointing but predictable statistic. To some extent, this could be attributed to shortcomings in the AJOL service, being a small organization with limited resources. That said, AJOL's communication with active participants is excellent (in fact an important strength), so it is likely that shortcomings in AJOL itself are not a very significant factor in journals becoming inactive. It is safe to assert that the primary reason for the sporadic or discontinued publishing on the part of many African journals is the enormous systemic difficulties facing scholarly research and research dissemination in Africa.

Evaluations of the AJOL programme show that research produced in African journals has been made more visible and accessible by the AJOL website. The data collected from the registrations, document deliveries 
(now downloads) and user questionnaires strongly indicate that AJOL has become established as a source of information not easily obtained otherwise. Many of AJOL's partner journals are not online anywhere else except on the AJOL site.

\section{Usability on the internet}

AJOL hosts its site and content on a virtual private server in the United States of America. This is so that users from the developed global North are able to use the site at a speed that is comparable for them to other similar resources. If AJOL were to host the service within Africa, the slow pace would be a real barrier to the use of the content. At the same time, AJOL has been careful to keep the site content as quick to download as possible for users from countries with very slow connectivity, and to ensure that the full text PDF files are kept very small, so that the downloads do not take too long for these users. Practical considerations of this kind are essential for the 'usability' of the African research contained on AJOL.

To some extent, the usage of the AJOL service is an indicator of how user-friendly the site is, as well as a measure of the need for the service and its visibility on the internet. For a small organisation of four full-time staff members, and a couple of people who contribute outsourced services on a part-time basis, the capability of the AJOL site is quite impressive in terms of volume and spread.

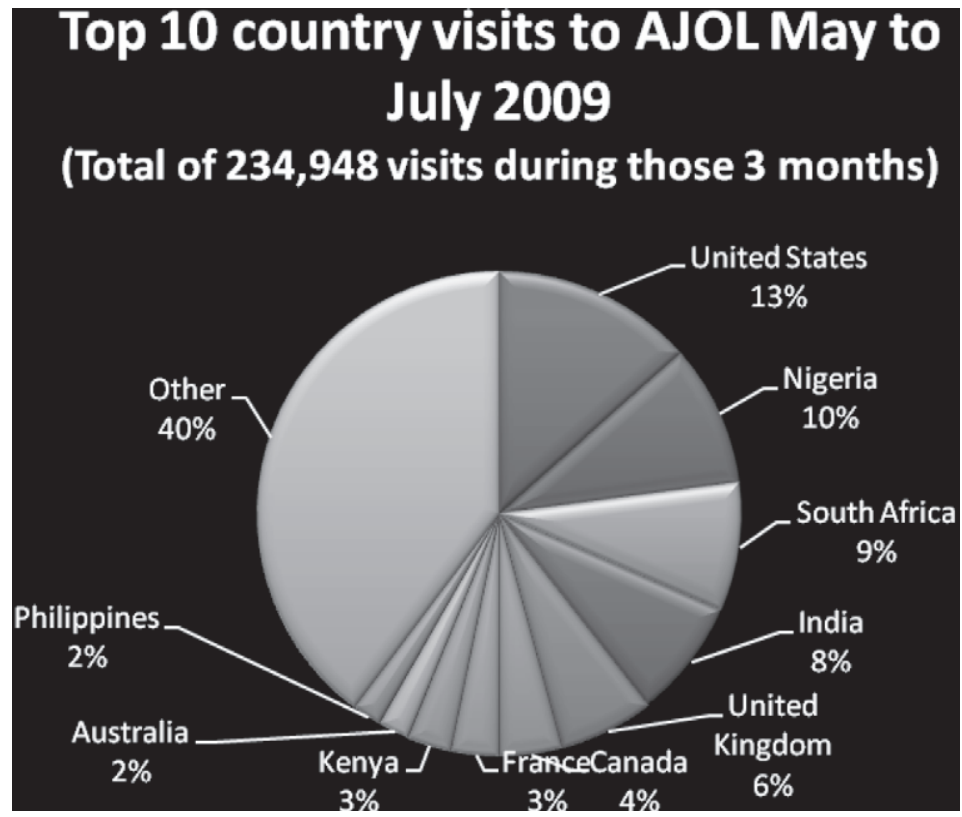




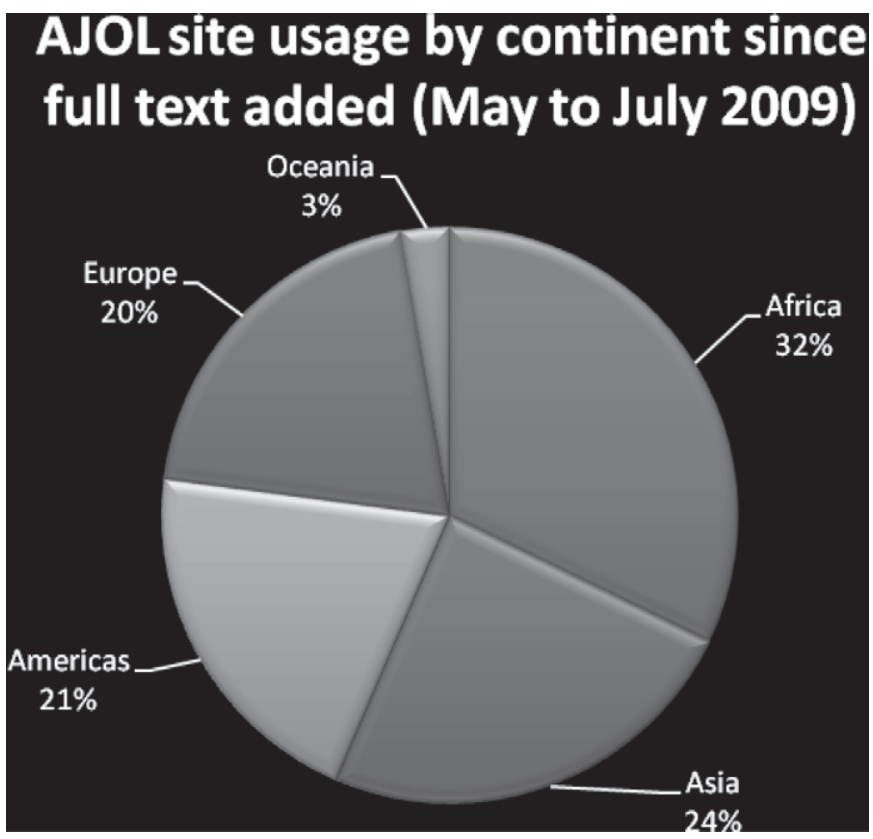

Another important usability element for journal staff, as opposed to readers and researchers using AJOL, is that of increasing the ease for journals to load content and manage their AJOL homepages themselves. This will involve the development of an 'off-line loading tool' in AJOL's open source software arsenal, and is planned for by the end of 2010 .

Despite understandable resentment by many, the languages of the colonialist countries continue to be the primary mode of instruction in African and international academe. The preferred use of vernacular languages to the exclusion of English, French and Arabic could isolate African academia from the rest of the world. The widespread adoption by journals, research organisations and universities of actionable policies to support both the relevant Western language and the vernacular language in their research dissemination would be advisable. ${ }^{40} \mathrm{AJOL}$ intends to encourage journals that publish online only, where the drive to reduce issue length to save on printing costs is no longer a constraint, to publish articles in both a local language (often the author's mother tongue) as well as an 'international' language depending on whether the country is Anglophone, Francophone or Lusophone. This will boost both local and international 'usability' of the content.

\section{Affordability}

Open Access - free full text access - is key to affordability of research outputs for academics from developing countries, where widespread poverty is

40 Teferra, D (2003) 'Scientific Communication and Research in African Universities: challenges and opportunities in the twenty-first century', in D Teferra and P.G. Altbach (eds), African Higher Education: an international reference handbook. Bloomington: Indiana University Press. 
endemic. This is strongly reinforced by a recent study by Evans and Reimer in 2009, which showed that 'online open access publishing had the greatest effect in the developing Southern Hemisphere rather than the wealthy Northern and Western. The influence of Open Access was more than twice as strong in the developing world'. ${ }^{41}$ This is evidence for an argument from common sense: namely that researchers working under conditions of extreme resource scarcity are more likely to read and cite articles they can obtain for free than to cite toll-access articles, which they cannot afford. It is particularly important therefore, that the research conducted in and published from the African continent be as affordable as possible, preferably Open Access, so that African researchers and those in other developing countries can have access to the relevant materials they most need for their work.

Sixty of the 350 journals on AJOL are currently Open Access. With the recent AJOL upgrade to Open Journal Systems 2.2.2 from the Public Knowledge Project, AJOL will now be offering all Open Access partner journals free hosting of the entire publishing work flow process by 2010 . This will be a considerable boost for participating journals, and, it is hoped, a stimulus in assisting journals in the transition from subscription-based to Open Access publishing models.

AJOL also provides a limited quota of free full text articles from subscription-based partner journals to researchers and librarians from Low Income Countries. The pricing of the rest of the individual article downloads is progressive, with High Income Country researchers paying the highest rates. Income, less some AJOL cost-recovery, is repatriated to the originating journals. The bibliographic meta-data database and journal information on the AJOL site is and will continue to be Open Access and the journals do not pay anything towards the running of the service.

There is huge diversity in journal publishing in Africa, with some journals being unassailably excellent by Western standards, with consistently good Thomson Reuters Impact Factors (IF) ${ }^{42}$ being produced by large, wellfinanced societies or professional publishing houses. However, many of the journals publishing from Africa are exceedingly resource-poor and constantly on the very edge of not being able to continue publishing. This is not to say that the research they contain is not of value or necessarily of lesser quality; quite the opposite. For example, if a peer-reviewed journal publishes sound research relevant to important contextual issues, but the journal does not always publish its issues on time, the grammar and punctuation are not perfect - as those involved are not mother-tongue speakers of the publication language or budgets may not allow for professional copy and language editing - and the journal is not frequently cited in other ISI-rated journal papers, it would be regarded by typical 'global Northern' standards as being of mediocre or poor quality. Since it would not be ISI rated, it would not be

\footnotetext{
${ }^{41}$ Evans J.A. \& J. Reimer (2009) 'Open Access and Global Participation in Science', Science 323: 1025 .

42 'The Impact Factor, often abbreviated IF, is a measure reflecting the average number of citations to articles published in science and social science journals. It is frequently used as a proxy for the relative importance of a journal within its field, with journals with higher impact factors deemed to be more important than those with lower ones. The impact factor was devised by Eugene Garfield, the founder of the Institute for Scientific Information (ISI), now part of Thomson Reuters.' (From http:// en.wikipedia.org/wiki/Impact_factor)
} 
regarded as an important journal in its field. However, AJOL would argue that if the research it is publishing is good and relevant to locally important issues and not available elsewhere, then that journal is of high quality. Even if the content is not of sufficient global interest to warrant thousands of citations, and inclusion in Thomson Reuters list of journals with Impact Factors, which have to comply with the above-mentioned Northern 'quality' standards, this does not mean the content is not of high quality in the sense explained in this paper.

Often, these journals rely heavily on volunteerism from one or two immensely dedicated individuals. The only actual cash they have is that from the limited subscriptions they receive, and the bulk of this income is usually spent on printing costs. They tend to be risk averse and believe that it is preferable to continue publishing to a relatively small readership through subscription-based publishing than to try for much broader readership through an alternative business model that they fear might prove unsustainable and would take away their only source of actual (as opposed to limited 'in kind' institutional) funding. However, the benefits to moving to an online only Open Access publishing model are considerable given that this allows for far higher readership, wider visibility and awareness of the journal leading to increased submissions (and therefore improved journal quality), and massive cost reduction due to the removal of printing costs, which are frequently equivalent to the full amount the journal amasses from subscription income. There are several journals that have shifted from a subscription-based to an Open Access-based publishing model during their partnership with AJOL, using various different business plans. The most frequent transitions have been by established journals with strong advertising income, notably the medical journals. Some journals are Open Access online, but continue to print and charge subscriptions for hard copies in cases where their readership has a marked preference for continuing to purchase and maintain hard copy collections. There are some professional Open Access publishers on the continent, which are successfully managing quite large stables of journals, which is encouraging. AJOL has also noticed that a high proportion of the recently started journals applying for an AJOL partnership are Open Access.

Particularly in cases where journals' subscription income is equivalent to their printing costs, it seems to make sense for them to embrace the benefits of Open Access, abandon printing altogether, and make use of the free tools and support initiatives available to them to move to an online only Open Access model. In some cases, journals cannot implement an online Open Access model themselves, even with free software like Open Journal Systems, due to poor internet connectivity or not being able to afford hosting costs. In those instances, AJOL's new functionality allows for free hosting of Open Access journals. However, journals also understand that to shift solely to an organization like AJOL (AJOL's new system allows for both the full management process of journal publishing to be done online, hosted by AJOL for free for Open Access journals, and then full text on AJOL for free) is to rely on AJOL continuing in perpetuity. Although AJOL is working on a business model to allow just that in future, the funding for this is not yet secured. The issue boils down, as always, to the editors and publishers weighing up the risks. It is AJOL's experience that the vast majority of the 
journals in Africa are not trying to amass enormous profits like the huge publishing houses that caused the serials crisis; ${ }^{43}$ they just do not want African research to lose its vehicle for dissemination.

Three things are needed to make scholarly journal publishing more open in Africa, such that users of bibliographies can actually access the full text that is pointed to. Firstly, more information for African editors and publishers about Open Access, particularly about practical models and successful case studies in Least Developed Countries. This is why AJOL has added Open Access as a prominent section in the Resources for Journals section on its website. Secondly, reliable sources of alternative income streams to allow sustainable and viable transition to Open Access publishing models for journals in developing countries. In the case of AJOL, an endowment fund is being raised to render the service permanently available to allow journals the security of an ongoing service in perpetuity. And finally, improved use and more widespread understanding of alternative licensing and copyright options for journals and authors to allow increased use of content.

\section{Some AFOL successes in South-South and South-North flow of scholarly information}

Beyond the continent-wide partnerships with African-published journals and the provision of online content, AJOL is striving to forge the all-important active collaborations, partnerships and linkages with African and international bodies to pro-actively increase South-South and South-North information flow. Some examples of these are detailed below.

\section{CODESRIA and the African Citation Index}

A strong case has been made for the development of an African Citation Index. ${ }^{44}$ The Council for the Development of Social Science Research in Africa (CODESRIA $)^{45}$ is taking a pro-active and long-term approach to bringing this to fruition. While citation frequency is an imperfect measure of the importance and quality of a journal, an index of this kind can be used for other purposes too, such as identifying regional research competencies and improving understanding of patterns of regional knowledge exchange, allowing insights on how to improve these. AJOL hopes that its new full text online and DOI functionality will assist with this work, and is developing a Memorandum of Understanding to guide future collaboration with CODESRIA. CODESRIA publishes ten scholarly journals, some of which are currently on AJOL.

\footnotetext{
${ }^{43}$ The term 'serials crisis' has become common shorthand to describe the systemic phenomenon of rapidly increasing institutional and library subscription costs of scholarly journals while library budgets have remained static or even decreased. This has resulted in many cases of library cancellations of some subscriptions to maintain others in the face of price increases, thus reducing overall access to research content.

${ }^{44}$ W. E. Nwagwu (2006) 'Organising and Monitoring Research Production and Performance in Africa: towards Africa citation index’, <http://www.codesria.org/Links/conferences/electronic publishing06/papers/Williams_Nwagwu.pdf $>$

$45<$ http://www.codesria.org/>
} 
Africa Science Trackers (AST)

The mission of AST ${ }^{46}$ is to track and index all scholarly output in peerreviewed journals published in Africa, or with their origins and focus on the African continent; to develop a database of African scholars on the continent and elsewhere, and to conduct research and consultancy services in higher education, science and technology. An African bibliometric database and scholars' database will not only provide scholars on the continent with a single comprehensive reference resource guide for various academic and research needs, but will also link scholars on the continent and beyond, through collaborated research and sharing of resources. AST has so far indexed over 35,000 articles and other document types (e.g. letters, notes, reviews, reports) in ACCESS and MySQL. The index is limited only to metadata in tables that include the following: author(s), title of article, full address of authors (e.g. country, institution), publication year, journal, field of study, among other things. Output indexes cover documents from the year 2000 onwards. The goal is to index close to 200,000 articles by the end of 2010 . AJOL and AST are in the process of defining the terms of a partnership to work together in these critical areas.

WorldWideScience Alliance

'WorldWideScience.org is a global science gateway-accelerating scientific discovery and progress through a multilateral partnership to enable federated searching of national and international scientific databases and portals.' AJOL was a founding Member of the WorldWideScience Alliance, which 'provides a geographically-diverse governance structure to promote and build upon the original vision of a global science gateway'. ${ }^{47}$ By being involved in the governance structure, AJOL was able to bring insights from the global South to the table, which helped to lower membership fees for organizations and institutions from the developing world, thus making for equitable representation. Including research content from Africa in this global online partnership was an important milestone for AJOL.

\section{Africa Bibliography}

AJOL has been informed that this valuable annual bibliography relies heavily on information from AJOL for the African-published journal data included in the bibliography. The fact that this subject bibliography is distributed free of charge to 40 African university libraries is a wonderful example of the SouthNorth information flow reinforcing South-South flow, since the bibliography points to, amongst other resources, an African-based, African-accessible resource in the form of AJOL. Africa Bibliography will be published as a searchable online database from 2011, with retrospective inclusion of backvolumes (all data compiled since 1984). DOIs will be included to allow for direct linking to articles/journal urls, including for all AJOL titles.

\section{Referring sites}

AJOL is included in the library's online resources section of many of the world's greatest institutions of higher education. There are many other sites

\footnotetext{
${ }^{46}<$ http://africasciencetrackers.com/>

$47<$ http://worldwidescience.org/alliancemembers.html>
} 
that have links to AJOL. Google Scholar sends a lot of traffic to the site. AJOL is OAI-PMH compliant (Open Archives Initiative Protocol on Meta-data Harvesting); this is extremely useful because it allows other online information initiatives to collect metadata of the papers in AJOL partner journals, which in turn gives greater online exposure to the research and the journals.

\section{Conclusion}

Online digital library organisations like AJOL are assisting with making use of the internet in terms of increasing the international visibility of Africanpublished, peer-reviewed journals, but no single organisation can achieve what is necessary in isolation and without support from and collaboration with similar initiatives, African policy-makers and governments, universities, research organisations, bibliographers, donors and the people actually directly involved in the production of the journals themselves. In analysing how to improve the number and visibility of African journals on the internet, it is important to recognize the complexity and multiplicity of factors for Africa to move closer to the centre of the international knowledge system. The advent of the internet in the 1990s appeared to be an opportunity to help overcome challenges involved in increasing access to African-published journals. However, a couple of decades on, there is still much room for improvement in publishing African journals online. The internet, open source software and imminent radical advances in ICT infrastructure and connectivity in Africa do and will assist in this vital work, but it should be remembered that these are merely the tools of the information age.

Bibliographies, whether in print, or online, are also tools to allow access to information. It is the pro-active, systemic, organized and strategic use of these tools that will determine the future of Africa's moving closer to the centre of the global knowledge system. To be accessible in the information age, African journals must ensure they are available, visible and usable on the internet, most particularly through striving towards Open Access of African-published materials, such that Africans themselves can read context-specific, relevant work from their own continent. Role-players in the continent's system of knowledge generation and dissemination hold the ultimate responsibility and moral burden to build on existing capacity through cooperation and collaboration. It is only by addressing the complex and multiple requirements at all levels that optimal use of opportunities will be attained and the African continent will be brought to prominence in the global knowledge system. 